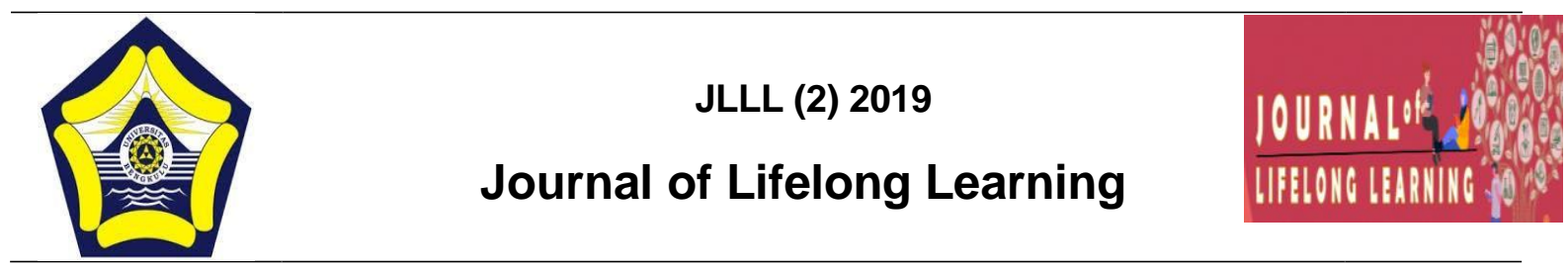

\title{
PELAKSANAAN PELATIHAN TES CALON PEGAWAI NEGERI SIPIL (CPNS) DENGAN SISTEM COMPUTER ASSISTED TEST (CAT) PADA LEMBAGA KURUS PELATIHAN (LKP) CORIEN CENTER
}

\author{
Ejra L Oktutula ${ }^{1}$, Aguz Z Rachmat ${ }^{2}$, Sofino ${ }^{3}$ \\ ${ }^{1}$ Nonformal Education, University of Bengkulu, Indonesia, Eljraoktutula@gmail.com \\ ${ }^{2}$ Nonformal Education, University of Bengkulu, Indonesia, aguszainal@gmail.com \\ ${ }^{3}$ Nonformal Education, University of Bengkulu, Indonesia, sofino@gmail.com
}

\begin{abstract}
The purpose of this study was to determine how the implementation of CPNS test on Corien Center LKP in Bengkulu City with research problems which included persriapan, trained preparation's, how the trainer demonstrated the material and the traine's efforts so that participants could practice the material in conducting test training CPNS system (CAT) Computer Assisted Test on LKP Corien Center used research with a case study method, data collection was carried out through interviews, observation and documentation. To test the data validation the researcher used triangulation techniques. The informants in this study were four people. Based on the results of the discussion, it can be concluded that : the trainer must prepare in the implementation of the training, namely modules (whiteboard markers and erasers), in the implementation of CPNS system test training (CAT) Computer Assisted Test on the Corien Center LKP the training participants must prepare, namely learning equipment in the form (pens, nptebooks) and bring the modules peovided by the institution, in the implementation of the training the tainers demonstrate the training material that is mastering the training material and preparing the necessary media so that the deliverwd material can be distributed to trainees, then in the implementation of an effort training carried out by the trainer so that the training participants could (CAT) Computer Assisted Test on the Corien Center LKP that is by using a method and strategy that is suitable whit teaching and learning activities.
\end{abstract}

Keywords : CPNS CAT Test Training LKP Corien Center 


\section{PENDAHULUAN}

LKP Corien Center eksis dari tahun 1983 berawal dari Corien Salon, kemudian berkembangan menekuni berbagai bidang seperti ; Corien Traning Center, Corien Psikologi Center, Corien Outbound Center, SDM, Corien Learning Center, PAUD dan TPA Ceria, pusat curhat remaja ceria, kelompok Usaha Aksisoris, sehingga menjadi menjadi Lembaga kursus pelatihan (LKP) pada tahun 2006.LKP Corien Center Kota Bengkulu mempunyai program pelatihan tes CAT, Pada pelatihan tes dengan sistem Computer Assisted Test (CAT) lembaga kursus dan pelatihan (LKP) Corien Center ini meliputi : Tes CPNS, polisis, tentara, BUMN, masuk dunia kerja, dan masuk perguruan tinggi favorit, namun pada penelitian ini peneliti lebih memfokuskan ke program pelaksanaan pelatihan tes CPNS sistem (CAT) Computer Assisted Test.

pelatihan tes CPNS LKP Corien Center ini pertama kali diselengarakan pada tahu 2006 yang pada saat itu masih sistem manual. kemudian pada tahun 2017 berkembang dengan sistem (CAT) Computer Assisted Test dan mempunyai peresta berjumlah 81 orang dan yang lulus dan melapor sebanyak 12 orang kemudian 2018 peserta yang mengikuti kursus pelatihan tes CPNS di Lembaga Kursus pelatihan Corien Center berjumlah 257 orang, dapat di artikan bahwa program pelatihan ini berkembang dan mempunyai peminat yang meningkat, walaupun biaya yang harus di keluarkan peserta kursus pelatihan cukup besar yaitu Rp. 1.250.000. Dengan data tersebut peneliti berminat mengangkat judul "Pelaksanaan Pelatihan tes Calon Pegawai Negeri Sipil (CPNS) dengan sistem Computer Assisted Test (CAT)"

1. Menurut Coombs dalam Sudjana (2010:21) :Pendidikan Nonformal ialah setiap kegiatan yang sistematis, di luar sistem persekolahan yang mapan, dilakukan secara mandiri atau merupakan bagian penting dari kegiatan yang lebih luas, yang sengaja dilakukan untuk melayani peserta didik tertentu di dalam mencapai tujuan belajarnya.

2. Menurut Wilson Bangun (2012:23) tentang manajemen sumber daya manusia yaitu Manajemen sumber daya manusia adalah pelaksanaan dan bertanggumg jawab atas kegiatan-kegiatan sumber daya manusia mulai dari pengadaan, pelatihan dan pengembangan, sampai pemisahan tenaga kerja.

3. Menurut peraturan pemerintah nomor 73 Tahun 1991 dalam Djudju Sudjana (2008:5) tentang pendidikan kedinasan yaitu :'Pendidikan kedinasan merupakan pendidikan yang berusaha meningkatkan kemampuan dalam pelaksanaan tugas kedinasan untuk pegawai atau calon pegawai suatu Departemen atau Lembaga Nondepartemen. Jenis ini pada umumnya dilakukan melalui program pelatihan".

4. Menurut Oemar Hamalik (2005:10) :"Pelatihan adalah suatu proses yang meliputi serangkaian tindakan (upaya) yang dilaksanakan dengan sengaja dalam bentuk pemberian bantuan kepada tenaga kerja peserta dalam bidang pekerjaan tertentuan guna meningkatkan efektifitas dan produktivitas dalam suatu organisasi".

5. Menurut Wilson Bangun (2012:206) tentang pelaksanaan pelatihan yaitu : Pelaksanaan pelatihan adalah proses pendekatan dengan melibatkan anggota didalam organisasi yang 
telah berpengalaman dalam memberikan ilmu sesuai kebutuhan organisasi dengan memperhatikan beberapa bidang meliputi biaya, waktu, dan lamanya pelatihan.

\section{METODE}

Penelitian ini menggunakan metode penelitan kualitatif. Pada penelitian ini, terdapat empat orang subjek yaitu Ibuk Dr.HC. Miswari, sebagai ketua umum Lembaga Kursus pelatihan Corien Center, Ibuk Rianti S.Psi sebagai Supervisor Pelalatihan Lembaga, Ibuk Ceni Fitri Utami, S. Psi Tutor Pelatihan dan Hendri Yulizar sebagai peserta pelatihan tes Calon Pegawai Negeri Sipil (CPNS) dengan sistem Computer Assisted Test pada Lembaga Kursus Pelatihan (LKP) Corien Center Kota Bengkulu. Teknik pengumpulan data menggunakan wawancara, observasi dan dokumentasi. Teknik analisis data dengan reduksi data, penyajian data dan penarikan kesimpulan. Pemeriksaan keabsahan dengan teknik triangulasi mulai dari triangulasi subjek, triangulasi waktu dan triangulasi teknik.

\section{HASIL DAN PEMBAHASAN}

Berdasarkan temuan dilapangan dengan pengumpulan data melalui hasil wawancara, observasi dan dokumentasi, penulis dapat mengambil kesimpulan bahwa:

1. Yang dipersiapkan pelatih adalah peralatan belajar mengajar berupa (modul, spidol, dan juga penghapus papan tulis) serta ada yang membantu pelatih dalam mempersiapka pelaksanaan pelatihan yaitu Muhammad Muchtiy Primbadha selaku bagian prasarana lembaga.Kemudian dalam hal hambatan pelatih dalam mempersiapakan pelaksanaan pelatihan tes CPNS sistem (CAT) Computer Assisted Test pada LKP Corien Ceneter ini ada,sesuai dengan jawaban informan bahwa yang menjadi hambatan pelatih dalam mempersiapkan pelaksanaan tes CPNS sistem (CAT) Computer Assisted Test yaitu penyusunan modul yang sesuai dengan kurikulum dari peraturan pemerintah.

2. yang harus dipersiapkan peserta pelatihan adalah peralatan belajar berupa (pena, buku catatan, buku latihan) serta membawa modul yang diberikan oleh lembaga, selanjutnya ada wewenang dari peserta pelatihan untuk memilih jadwal pelatihan sesuai dengan kebutuhannya dan tidak ada pembagian kelas bagi peserta pelatihan. Kemudian dalam hal mempersiapakan diri dalam pelaksanaan pelatihan tes CPNS sistem (CAT) Computer Assisted Test pada LKP Corien Ceneter ini peserta pelatihan tidak ada hambatan. Sesuai dengan jawaban informan bahwa segalah hal yang berhubungan dengan persiapan pelaksanaan pelatihan tes CPNS sistem (CAT) Computer Assisted Test adalah tanggung jawab dari lemabaga.

3. cara yang dilakukan pelatih dalam mempragakan materi pelatihan yaitu dengan menguasai materi pelatihan dan menyiapkan media yang diperlukan agar meteri yang disampaikan dapat diterima oleh peserta pelatihan. Kemudian dalam hal memperagakan materi pelatihan tes CPNS sistem (CAT) Computer Assisted Test pada LKP Corien Ceneter ini pelatih ada kendala. Sesuai dengan jawaban informan bahwa Kendala yang dihadapi pelatih adalah tingkat kemampuan peserta palatihan dalam menerima materi palatihan yang tidak sama. 
4. agar peserta bisa mempraktikkan materi pelatihan yaitu dengan menggunakan metode dang strategi yang sesuai dengan kegiatan belajar mengajar dan juga memberikan motivasi dengan mendatangkan alumni peserta pelatihan yang lulus PNS melalui Frofisional tim Lembaga.

\section{PENUTUP KESIMPULAN}

Berdasarkan temuan penelitian dan pembahasan dapat diambil kesimpulan yaitu: Hasil penelitian menemukan bahwa dalam pelaksanaan pelatihan tes Calon Pegawai Negeri Sipil (CPNS) dengan sistem Computer Assisted Test (CAT) yang harus dipersiapkan pelatih yaitu Modul dan alat belajar mengajar berupa (modul, spidol dan penghapus papan tulis), pelatih juga ada yang membantu dan bertanggung jawab dalam mempersipkan pelaksanaan pelatihan yaitu bagian sarana prasaran yaitu bapak Muhammad Muchti Priambadha, pelatih juga ada hambatan dalam mepersiapkan pelaksanaan pelatihan yaitu penyusunan modul dan juga cancel mendadak peserta pelatihan, yang harus peserta pelatihan siapkan yaitu peralatan belajar berupa (pena, buku catatan, buku latihan) serta membawa Modul yang diberikan oleh lembaga, dalam memilih jadwal pelatihan ada wewenang sesuai dengan kebutuhan peserta, tidak ada pembagian kelas terhadap peserta pelatihan, Serta peserta pelatihan tidak ada hambatan, selanjutanya upaya yang dilakukan pelatih yaitu menguasai materi pelatihan, pelatih juga memerlukan bantuan media, media yang di perlukan yaitu papan tulis kemudia media penenarang pada rungangan yang gelap, adapun media yang efektif digunakan adalah media papan tulis, pelatih juga mengalami hambatan dalam memperagakan pelatihan yaitu tingkat kemapuan pemahaman peseta pelatihan yang berbeda serta menggunakan Metode ceramah, tanya jawab dan latihan menjawab soal-sola yang berhubungan dengan tes CPNS, pelatih juga menggunakan Strategi yang biasa digunakan dalam kegiatan belajatr mengajar, strategi yang digunakan yaitu strategi induktif dan strategi deduktif serta melakukan pemberian motivasi melalui frofisional tim di LKP Corien Center yaitu dengan mendatangkan alumni pelatihan yang lulus dari tes CPNS.

\section{REFERNSI}

Akh. Wayne Mondy .2008. Manajemen Sumber Daya Manusia Jilid 1 Edisi 10.Jakarta : Erlangga

Abdurahmat Fathoni. 2006. Manajemen Sumber daya Manusia.Bandung Rineka Cipta.

Djudju Sudjana .2006. Evaluasi Program Pendidikan Luar Sekolah. Bandung: PT Remaja Rosdakarya.

Hani. T. Handoko. (2003). Manajemen Edisi 2.Yogyakarta : Anggota IKAPI No.003

Hamalik, Oemar.2005. Manajemen Pelatihan Ketenaga Kerjaan. Jakarta: bumi Aksara.

Ricki, W. Griffin. 2002. Manajemen Pelatihan Ketenaga Kerjaan, Jilid 1.Texsas A \& M University : Erlangga.

Raymond A. Noe, dkk. 2010. Manajemen Sumber Daya Manusia Mencapai Keunggulan Bersaing. Jakarta: McGraw-Hill Education (asia) And Selemba Empat 
Simamora, Henry. (2006). Manajemen Sumber Daya Manusia Edisi 2.Yogyakarta : STIE YKPN.

Sri Teguh Waluyo. 2016. Manajemen Training; teknik praktis pengelolaan Training dan pelatihan sumber daya. Bandung: PT SEWU (Srikandi Empat Widiya Utama)

Sedarmayanti.2016. Manajemen Sumber Daya Manusia Reformasi Birokrasi dan Manajemen Pegawai Negeri Sipil edisi Rivisi. Bandung: PT Refika Aditama.

Sedarmayanti. 2017. Perencanaan dan Pengembangan SDM untuk Meningkatkan Kompetensi, kinerja, dan Produktivitas Kerja. Bandung: PT Refika Aditama.

S.Jauvani Ella, Rivai Vaithzal .2009. Manajemen Sumber Daya Manusia untuk Perusahaan. Jakarta: PT Raja Grapindo Persada.

Sugiyono .2014.Metode Penelitian Kuantitatif dan Kualitatif.Bandung : Alpabeta.

Sudjana .2010.Pendidikan NonFormal.Bandung : Falah Production.

Tim Pustaka Cerdas. 2019. Kisi-kisi Resmi Tes CPNS Tenaga Medis. Yogyakarta: Pustaka Baru Press.

Tim Edu Penguin. 2019. Master Sukses CAT CPNS 2019-2020. Jakarta: Edu Penguin. 